\title{
A new consensus for Trypanosoma cruzi intraspecific nomenclature: second revision meeting recommends Tcl to TcVI
}

\author{
B Zingales ${ }^{1 /}{ }^{+}$, SG Andrade ${ }^{2}$, MRS Briones ${ }^{3}$, DA Campbell ${ }^{4}$, E Chiari $^{5}$, O Fernandes ${ }^{6}$, F Guhl$^{7}$, \\ E Lages-Silva ${ }^{8}$, AM Macedo ${ }^{9}$, CR Machado ${ }^{9}$, MA Miles ${ }^{10}$, AJ Romanha ${ }^{11}$, NR Sturm ${ }^{4}$, \\ M Tibayrenc ${ }^{12}$, AG Schijman ${ }^{13}$
}

\begin{abstract}
${ }^{1}$ Departamento de Bioquímica, Instituto de Química, Universidade de São Paulo, São Paulo, SP, Brasil ${ }^{2}$ Centro de Pesquisas Gonçalo Moniz, Fundação Oswaldo Cruz-Fiocruz, Salvador, BA, Brasil ${ }^{3}$ Departamento de Microbiologia, Imunologia e Parasitologia, Universidade Federal de São Paulo, São Paulo, SP, Brasil ${ }^{2}$ Department of Microbiology, Immunology and Molecular Genetics, David Geffen School of Medicine, University of California, Los Angeles, CA, USA ${ }^{5}$ Departamento de Parasitologia ${ }^{9}$ Departamento de Bioquímica e Imunologia, Instituto de Ciências Biológicas, Universidade Federal de Minas Gerais, Belo Horizonte, MG, Brasil ${ }^{6}$ Laboratório Interdisciplinar de Pesquisas Médicas, Instituto Oswaldo Cruz-Fiocruz, Rio de Janeiro, RJ, Brasil Centro de Investigaciones en Microbiología y Parasitología Tropical, Facultad de Ciencias, Departamento de Ciencias Biológicas, Universidad de los Andes, Bogotá, Colombia ${ }^{8}$ Departamento de Ciências Biológicas, Universidade Federal do Triângulo Mineiro, Uberaba, MG, Brasil ${ }^{10}$ Pathogen Molecular Biology Unit, London School of Hygiene and Tropical Medicine, London, UK ${ }^{11}$ Instituto de Pesquisas René Rachou-Fiocruz, Belo Horizonte, MG, Brasil ${ }^{12}$ Laboratory of Genetics and Evolution of Infectious Diseases, UMR IRD/CNRS 2724, Montpellier, France ${ }^{13}$ Laboratorio de Biología Molecular de la Enfermedad de Chagas, Instituto de Ingeniería Genética y Biología Molecular, CONICET, Buenos Aires, Argentina
\end{abstract}

In an effort to unify the nomenclature of Trypanosoma cruzi, the causative agent of Chagas disease, an updated system was agreed upon at the Second Satellite Meeting. A consensus was reached that $\mathrm{T}$. cruzi strains should be referred to by six discrete typing units (T. cruzi I-VI). The goal of a unified nomenclature is to improve communication within the scientific community involved in $\mathrm{T}$. cruzi research. The justification and implications will be presented in a subsequent detailed report.

Key words: Chagas disease - Trypanosoma cruzi strains - taxonomy - discrete typing units

The biological, biochemical and genetic diversity of Trypanosoma cruzi strains has long been recognised, along with their eco-epidemiological complexity, which has been reviewed extensively elsewhere (Macedo \& Pena 1998, Campbell et al. 2004, Miles et al. 2009). Over the years, numerous approaches have been used to characterise the population structure of T. cruzi, aiming at defining the number of relevant subgroups. Accordingly, these subgroups received different designations, including zymodemes (Miles et al. 1977, 1978, 1981, Romanha et al. 1979), schizodemes (Morel et al. 1980), biodemes (Andrade 1974, Andrade \& Magalhães 1997), clonets (Tibayrenc \& Ayala 1991), lineages (Souto et al. 1996), clades (Kawashita et al. 2001) and, more recently, discrete typing units (DTUs) (Tibayrenc 1998) and haplotypes (Freitas et al. 2006, Herrera et al. 2007).

In a Satellite Meeting held at Fiocruz in 1999, an expert committee reviewed the available knowledge that indicated a convergence toward clustering T. cruzi strains into two major groups. Recommendations were issued that can be summarised as follows (Anonymous 1999). $T$. cruzi strains characterised by biological and biochemical features (e.g., biodemes and zymodemes) and molecu-

+Corresponding author: zingales@iq.usp.br

Received 28 September 2009

Accepted 7 October 2009 lar techniques [e.g., multilocus enzyme electrophoresis (MLEE), random amplification of polymorphic DNA (RAPD), mini-exon and $24 \mathrm{~S} \alpha$ ribosomal DNA sequences] should be classified into two principal groups, named T. cruzi I and T. cruzi II. The classification of apparent hybrid strains and strains equivalent to Zymodeme 3 (Miles et al. 1978, 1981) and Biodeme Type I (Andrade 1974) would be decided later after further studies.

In the 10 years that followed the meeting at Fiocruz, the scientific community has advanced in the knowledge of T. cruzi diversity. Multilocus genotyping has revealed six distinct DTUs, which partition into two major subdivisions, termed DTU I and DTU II. DTUs are defined as "sets of stocks that are genetically more related to each other than to any other stock and that are identifiable by common genetic, molecular or immunological markers" (Tibayrenc 1998). T. cruzi DTU II was further split into five DTUs, IIa-e (Brisse et al. 2000, 2001), based on congruent phylogenetic information from MLEE and RAPD markers. DTUs I and IIb correspond, respectively, to the $T$. cruzi I and $T$. cruzi II groups recommended by the original expert committee in 1999 (Table I). Current studies indicate that four subdivisions have emerged within DTU I as well (Herrera et al. 2007, Falla et al. 2009), although these have not been integrated into the nomenclature revision.

Although the major genetic variability of $T$. cruzi was proposed initially to have resulted from predominant clonal evolution (Tibayrenc et al. 1986), increasing evidence indicates that genetic exchange between parasites has contributed to the present popu- 
TABLE I

2009 nomenclature for Trypanosoma cruzi divisions

\begin{tabular}{|c|c|c|}
\hline DTU designation & Abbreviation & Equivalence to former $T$. cruzi grouping schemes \\
\hline T. cruzi I & TcI & 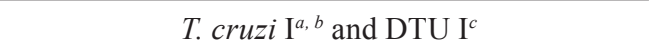 \\
\hline T. cruzi II & TcII & T. cruzi $\mathrm{II}^{a}$ and DTU $\mathrm{IIb}^{c}$ \\
\hline T. cruzi III & TcIII & 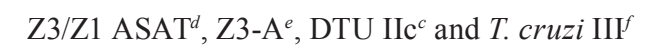 \\
\hline T. cruzi IV & TcIV & 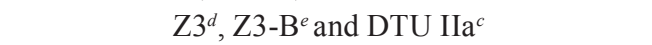 \\
\hline T. cruzi V & $\mathrm{TcV}$ & Bolivian Z2 $2^{d}$, rDNA $1 / 2^{g}$, clonet $39^{h}$ and DTU $\operatorname{IId}^{c}$ \\
\hline T. cruzi VI & TcVI & Paraguayan $\mathrm{Z2}^{i}$, Zymodeme B ${ }^{i}$ and DTU $\mathrm{IIe}^{c}$ \\
\hline
\end{tabular}

$a$ : Anonymous 1999; $b$ : Falla et al. 2009; $c$ : Brisse et al. 2000; $d$ : Miles et al. 1981; DTU: discrete typing units; $e$ : Mendonça et al. 2002; $f$ :Freitas et al. 2006; $g$ : Souto et al. 1996; $h$ : Tibayrenc and Ayala 1991; $i$ : Chapman et al. 1984 ; $j$ : Carneiro et al. 1990.

lation structure (Sturm \& Campbell 2009). This was first documented by the existence of hybrid organisms in sylvatic $T$. cruzi populations and sympatric clinical strains and, later, experimentally (Gaunt et al. 2003 and cited references). The prevailing view is that DTU I and DTU IIb are ancient lineages and that DTU IId and DTU IIe strains are the products of a minimum of two hybridisation events (Westenberger et al. 2005, Freitas et al. 2006, Tomazi et al. 2009). The evolution of DTU IIa and DTU IIc strains is insufficiently understood for the moment, although these DTUs may also have a hybrid origin (Sturm et al. 2003, Westenberger et al. 2005). Based on microsatellite and mitochondrial DNA analyses, DTU IIc may represent a third ancestral lineage, which was named $T$. cruzi III (Freitas et al. 2006).

The advances in the understanding of $T$. cruzi population structure indicate that it is time to revise the nomenclature of T. cruzi strains. The standardisation of nomenclature will facilitate communication among researchers working with $T$. cruzi aimed at characterisation of its eco-epidemiological features, pathogenicity and questions of basic biology.
A Second Satellite Meeting was held in Buzios, Brazil, on August 23, 2009, preceding the XIII International Congress of Protistology, the XXV Annual Meeting of the Brazilian Society of Protozoology and the XXXVI Annual Meeting on Basic Research in Chagas Disease. By consensus, the expert committee recognised that the nomenclature for $T$. cruzi strains should be classified into six DTUs, T. cruzi I-VI and issued recommendations accordingly. Detailed justification and implications of these decisions will be presented in a future publication.

Recommendations of the Second Satellite Meeting - (i) The known isolates and strains of T. cruzi should be assigned to one of six DTUs (T. cruzi I-VI). Additional variants may arise in the future; (ii) DTUs T. cruzi I and $T$. cruzi II correspond to the two groups originally defined in the First Satellite Meeting (Anonymous 1999). A notable exception is the CL Brener strain, classified at that time as $T$. cruzi II and now reclassified as T. cruzi VI; (iii) The designation of the six DTUs, their abbreviations and equivalence are summarised in Table I; (iv) Authors and reviewers of manuscripts describing studies on T. cruzi are encouraged to use the new nomenclature; (v) Editors of sci-

TABLE II

Representative strains and corresponding discrete typing units (DTUs)

\begin{tabular}{|c|c|c|c|}
\hline Strain $^{a}$ & DTUs & Country & Host/vector \\
\hline $12 \mathrm{SF}$ & T. cruzi II & Bahia, Brazil & Homo sapiens \\
\hline $21 \mathrm{SF}$ & T. cruzi II & Bahia, Brazil & Homo sapiens \\
\hline 3663 & T. cruzi III & Amazonas, Brazil & Panstrongylus geniculatus \\
\hline 3869 & T. cruzi III & Amazonas, Brazil & Homo sapiens \\
\hline 4167 & T. cruzi IV & Amazonas, Brazil & Rhodnius brethesi \\
\hline 4182 & T. cruzi III & Amazonas, Brazil & Rhodnius brethesi \\
\hline $92.80 \mathrm{cl} 2$ & T. cruzi $\mathrm{V}$ & Santa Cruz, Bolivia & Homo sapiens \\
\hline 92101601P cl1 & T. cruzi I & Georgia, USA & Didelphis marsupialis \\
\hline $92122102 \mathrm{R}$ & T. cruzi IV & Georgia, USA & Procyon lotor \\
\hline Bug2148 cl1 & T. cruzi $\mathrm{V}$ & Rio Grande do Sul, Brazil & Triatoma infestans \\
\hline Bug2149 cl10 & T. cruzi $\mathrm{V}$ & Rio Grande do Sul, Brazil & Triatoma infestans \\
\hline
\end{tabular}




\begin{tabular}{|c|c|c|c|}
\hline Strain $^{a}$ & DTUs & Country & Host/vector \\
\hline CA-1 & T. cruzi I & Argentina & Homo sapiens \\
\hline CanIII cl1 & T. cruzi IV & Pará, Brazil & Homo sapiens \\
\hline CL & T. cruzi VI & Rio Grande do Sul, Brazil & Triatoma infestans \\
\hline CL Brener $^{b}$ & T. cruzi VI & Rio Grande do Sul, Brazil & Triatoma infestans \\
\hline CM17 & T. cruzi III & Meta, Colombia & Dasypus sp. \\
\hline Colombiana & T. cruzi I & Colombia & Homo sapiens \\
\hline Cuica cl1 & T. cruzi I & São Paulo, Brazil & Philander opossum \\
\hline Cutia cl1 & T. cruzi I & Espírito Santo, Brazil & Dasyprocta aguti \\
\hline Davis 9.90 & T. cruzi I & Tegucigalpa, Honduras & Triatoma dimidiata \\
\hline $\operatorname{Dm} 28 \mathrm{c}^{c}$ & T. cruzi I & Carabobo, Venezuela & Didelphis marsupialis \\
\hline Dm7 & T. cruzi I & Casanare, Colombia & Didelphis marsupialis \\
\hline Dog Theis $^{d}$ & T. cruzi IV & Oklahoma, USA & Canis familiaris \\
\hline Esmeraldo $\mathrm{cl} 3$ & T. cruzi II & Bahia, Brazil & Homo sapiens \\
\hline G & T. cruzi I & Amazonas, Brazil & Opossum \\
\hline Gambá cl1 & T. cruzi I & São Paulo, Brazil & Didelphis azarae \\
\hline IVV cl4 & T. cruzi II & Cuncumen, Chile & Homo sapiens \\
\hline JEM C & T. cruzi I & Boyacá, Colombia & Homo sapiens \\
\hline José & T. cruzi I & Paraíba, Brazil & Homo sapiens \\
\hline K-98 & T. cruzi I & Argentina & Homo sapiens \\
\hline M5631 cl5 & T. cruzi III & Pará, Brazil & Dasypus novemcinctus \\
\hline M6241 cl6 & T. cruzi III & Pará, Brazil & Homo sapiens \\
\hline MAS cll & T. cruzi II & Minas Gerais, Brazil & Homo sapiens \\
\hline $\mathrm{MN}$ cl2 & T. cruzi $\mathrm{V}$ & Region IV, Chile & Homo sapiens \\
\hline NR $\mathrm{cl} 3$ & T. cruzi $\mathrm{V}$ & Salvador, Chile & Homo sapiens \\
\hline P63 cl1 & T. cruzi VI & Makthlawaiya, Paraguay & Triatoma infestans \\
\hline PALC & T. cruzi I & Casanare, Colombia & Rhodnius prolixus \\
\hline Peruvian & T. cruzi II & Peru & Homo sapiens \\
\hline RA & T.cruzi VI & Argentina & Homo sapiens \\
\hline Sc43 cl1 & T. cruzi $\mathrm{V}$ & Santa Cruz, Bolívia & Triatoma infestans \\
\hline $\mathrm{SO} 3 \mathrm{cl} 5$ & T. cruzi $\mathrm{V}$ & Potosi, Bolivia & Triatoma infestans \\
\hline Sylvio $^{f}$ X10 cl1 & T. cruzi I & Pará, Brazil & Homo sapiens \\
\hline $\mathrm{Td} 11 \mathrm{C}$ & T. cruzi I & Boyacá Colombia & Triatoma dimidiata \\
\hline Tu18 cl1 & T. cruzi II & Tupiza, Bolívia & Triatoma infestans \\
\hline Tulahuen & T. cruzi VI & Tulahuen, Chile & Homo sapiens \\
\hline Tulahuen cl2 & T. cruzi VI & Tulahuen, Chile & Homo sapiens \\
\hline $\mathrm{X} 10 / 1^{\mathrm{g}}$ & T. cruzi I & Pará, Brazil & Homo sapiens \\
\hline $\mathrm{X} 109 / 2$ & T. cruzi III & Makthlawaiya, Paraguay & Canis familiaris \\
\hline $\mathrm{Y}$ & T. cruzi II & São Paulo, Brazil & Homo sapiens \\
\hline $\mathrm{YuYu}$ & T. cruzi I & Minas Gerais, Brazil & Triatoma infestans \\
\hline
\end{tabular}

$a$ : the term cl following the name of the strain indicates it is a clone derived from the original isolate; $b$ : CL Brener is a clone derived from the CL strain; $c$ : Dm28c is a clone derived from the Dm28 strain; $d$ : Dog Theis sometimes shortened to DogT or DogTh; $e$ : K-98 is a clone derived from the CA-1 strain; $f$ : Sylvio referred to as Silvio; $g$ : same as Sylvio (Silvio) X10 cl1.

entific journals are encouraged to adopt the recommended nomenclature for the T. cruzi DTUs in their journals; (vi) Typing services should be made available for strains in the existing literature. A list of some reference and "experimental" strains and their corresponding designation is presented to serve as guide for researchers (Table II).

To obtain the greatest effectiveness, the new recommendations for the naming of $T$. cruzi will require a simple and reproducible schema for typing isolates into their respective DTUs. Lewis et al. (2009) described such a schema using currently available markers in the form of a triple assay that employed rDNA PCR (Souto et al. 1996) and PCR-RFLP of the HSP60 and GPI loci (Westenberger et al. 2005). The expert committee is exploring the possibility of a multicentric study to standardise and validate different protocols for genotyping reference and laboratory strains, as well as field isolates. Any multicentric study will make a call for comparative typing protocols that are under development currently in other laboratories. 


\section{ACKNOWLEDGEMENTS}

To the Brazilian Society of Protozoology and its President, Prof. Lucia Mendonça Previato (2008-2009), for organizational support of the Satellite Meeting, and to FINEP, Ministry of Health of Brazil, CNPq and Fiocruz, for underwriting the expenses of the Satellite Meeting participants.

\section{REFERENCES}

Andrade SG 1974. Caracterização de cepas do Trypanozoma cruzi isoladas no Recôncavo Baiano. Rev Patol Trop 3: 65-121.

Andrade SG, Magalhães JB 1997. Biodemes and zymodemes of Trypanosoma cruzi strains: correlations with clinical data and experimental pathology. Rev Soc Bras Med Trop 30: 27-35.

Anonymous 1999. Recommendations from a Satellite Meeting. Mem Inst Oswaldo Cruz 94 (Suppl. II): 429-432.

Brisse S, Barnabé C, Tibayrenc M 2000. Identification of six Trypanosoma cruzi phylogenetic lineages by random amplified polymorphic DNA and multilocus enzyme electrophoresis. Int $J$ Parasitol 30: 35-44.

Brisse S, Verhoef J, Tibayrenc M 2001. Characterization of large and small subunit rRNA and mini-exon genes further supports the distinction of six Trypanosoma cruzi lineages. Int J Parasitol 31: $1218-1226$.

Campbell DA, Westenberger SJ, Sturm NR 2004. The determinants of Chagas disease: connecting parasite and host genetics. Curr Mol Med 4: 549-562.

Carneiro M, Chiari E, Gonçalves AM, da Silva Pereira AA, Morel CM, Romanha AJ 1990. Changes in the isoenzyme and kinetoplast DNA patterns of Trypanosoma cruzi strains induced by maintenance in mice. Acta Trop 47: 35-45.

Chapman M, Baggaley R, Godfrey-Fausset P, Malpas T, White G, Canese J, Miles M 1984. Trypanosoma cruzi from the Paraguayan Chaco: isoenzyme profiles of strains isolated at Makthlawaiya. J Protozool 31: 482-486.

Falla A, Herrera C, Fajardo A, Montilla M, Vallejo GA, Guhl F 2009. Haplotype identification within Trypanosoma cruzi I in Colombian isolates from several reservoirs, vectors and humans. Acta Trop 110: 15-21.

Freitas JM, Augusto-Pinto L, Pimenta JR, Bastos-Rodrigues L, Gonçalves VF, Teixeira SM, Chiari E, Junqueira AC, Fernandes O, Macedo AM, Machado CR, Pena SD 2006. Ancestral genomes, sex and the population structure of Trypanosoma cruzi. PLoS Pathog 2: e24.

Gaunt MW, Yeo M, Frame IA, Stothard JR, Carrasco HJ, Taylor MC, Mena SS, Veazey P, Miles GAJ, Acosta N, Arias ARD, Miles MA 2003. Mechanism of genetic exchange in American trypanosomes. Nature 421: 936-939.

Herrera C, Bargues MD, Fajardo A, Montilla M, Triana O, Vallejo GA, Guhl F 2007. Identifying four Trypanosoma cruzi I isolate haplotypes from different geographic regions in Colombia. Infect Genet Evol 7: 535-539.

Kawashita SY, Sanson GFO, Fernandes O, Zingales B, Briones MRS 2001. Maximum-likelihood divergence data estimates based on rRNA gene sequences suggest two scenarios of Trypanosoma cruzi intraspecific evolution. Mol Biol Evol 18: 2250-2259.

Lewis MD, Ma J, Yeo M, Carrasco HJ, Llewellyn MS, Miles MA 2009. Genotyping of Trypanosoma cruzi: systematic selection of assays allowing rapid and accurate discrimination of all known lineages. Am J Trop Med Hyg, in press.

Macedo AM, Pena SDJ 1998. Genetic variability of Trypanosoma cruzi: implications for the pathogenesis of Chagas disease. Parasitol Today 14: 119-123.

Mendonça MB, Nehme NS, Santos SS, Cupolillo E, Vargas N, Junqueira A, Naiff RD, Barrett TV, Coura JR, Zingales B, Fernandes O 2002. Two main clusters within Trypanosoma cruzi zymodeme 3 are defined by distinct regions of the ribosomal RNA cistron. Parasitol 124: 177-184.

Miles MA, Cedillos RA, Povoa MM, Souza AA de, Prata AA, Macedo V 1981. Do radically dissimilar Trypanosoma cruzi strains (zymodemes) cause Venezuelan and Brazilian forms of Chagas disease? Lancet 317: 1338-1340.

Miles MA, Llewellyn MS, Lewis MD, Yeo M, Baleela R, Fitzpatrick S, Gaunt MW, Mauricio IL 2009. The molecular epidemiology and phylogeography of Trypanosoma cruzi and parallel research on Leishmania: looking back and to the future. Parasitol, 136: 1509-1528.

Miles MA, Souza AA de, Povoa MM, Shaw JJ, Lainson R, Toyé PJ 1978. Isozymic heterogeneity of Trypanosoma cruzi in the first autochthonous patients with Chagas disease in Amazonian Brazil. Nature 272: 819-821.

Miles MA, Toyé PJ, Oswald SC, Godfrey DG 1977. The identification by isoenzyme patterns of two distinct strain-groups of Trypanosoma cruzi circulating independently in a rural area of Brazil. Trans R Soc Trop Med Hyg 71: 217-225.

Morel C, Chiari E, Camargo EA, Mattei DM, Romanha AJ, Simpson L 1980. Strains and clones of Trypanosoma cruzi can be characterized by pattern of restriction endonuclease. Proc Natl Acad Sci USA 77: 6810-6814.

Romanha AJ, da Silva Pereira AA, Chiari E, Kilgour V 1979. Isoenzyme patterns of cultured Trypanosoma cruzi changes after prolonged subculture. Comp Biochem Physiol 62: 139-142.

Souto RP, Fernandes O, Macedo AM, Campbell DA, Zingales B 1996. DNA markers define two major phylogenetic lineages of Trypanosoma cruzi. Mol Biochem Parasitol 83: 41-152.

Sturm NR, Campbell DA 2009. Alternative lifestyles: the population structure of Trypanosoma cruzi. Acta Trop, in press.

Sturm NR, Vargas NS, Westenberger SJ, Zingales B, Campbell DA 2003. Evidence for multiple hybrid groups in Trypanosoma cruzi. Int J Parasitol 33: 269-279.

Tibayrenc M 1998. Genetic epidemiology of parasitic protozoa and other infectious agents: the need for an integrated approach. Int J Parasitol 28: 85-104.

Tibayrenc M, Ayala FJ 1991. Towards a population genetics of microorganisms: the clonal theory of parasitic protozoa. Parasitol Today 7: 228-232.

Tibayrenc M, Ward P, Moya A, Ayala FJ 1986. Natural populations of Trypanosoma cruzi, the agent of Chagas disease, have a complex multiclonal structure. Proc Nat Acad Sci USA 83: 115-119.

Tomazi L, Kawashita SY, Pereira PM, Zingales B, Briones MRS 2009. Haplotype distribution of five nuclear genes based on network genealogies and Bayesian inference indicates that Trypanosoma cruzi hybrid strains are polyphyletic. Genet Mol Res 8: 458-476.

Westenberger SJ, Barnabé C, Campbell D, Sturm NR 2005. Two hybridization events define the population structure of Trypanosoma cruzi. Genetics 171: 527-543. 